\title{
The Dual Role of Zonula Occludens (ZO) Proteins
}

\author{
H. Bauer, ${ }^{1}$ J. Zweimueller-Mayer, ${ }^{1}$ P. Steinbacher, ${ }^{1}$ A. Lametschwandtner, ${ }^{1}$ and H. C. Bauer ${ }^{1,2}$ \\ ${ }^{1}$ Department of Organismic Biology, University of Salzburg, Hellbrunner Strasse 34, 5020 Salzburg, Austria \\ ${ }^{2}$ Unit for Applied Cell Biology, Paracelsus Private Medical University, Salzburg, Austria \\ Correspondence should be addressed to H. Bauer, hannelore.bauer@sbg.ac.at
}

Received 14 July 2009; Accepted 6 January 2010

Academic Editor: Amanda McCann

Copyright () 2010 H. Bauer et al. This is an open access article distributed under the Creative Commons Attribution License, which permits unrestricted use, distribution, and reproduction in any medium, provided the original work is properly cited.

ZO (zonula occludens) proteins are scaffolding proteins providing the structural basis for the assembly of multiprotein complexes at the cytoplasmic surface of intercellular junctions. In addition, they provide a link between the integral membrane proteins and the filamentous cytoskeleton. ZO proteins belong to the large family of membrane-associated guanylate kinase (MAGUK)-like proteins comprising a number of subfamilies based on domain content and sequence similarity. Besides their structural function at cell-cell contacts, ZO proteins appear to participate in the regulation of cell growth and proliferation. Detailed molecular studies have shown that ZO proteins exhibit conserved functional nuclear localization and nuclear export motifs within their amino acid sequence. Further, ZO proteins interact with dual residency proteins localizing to the plasma membrane and the nucleus. Although the nuclear targeting of ZO proteins has well been described, many questions concerning the biological significance of this process have remained open. This review focuses on the dual role of ZO proteins, being indispensable structural components at the junctional site and functioning in signal transduction pathways related to gene expression and cell behavior.

\section{Introduction}

Epithelial and endothelial cells attach to each other by various occluding junctions which rely on the function of specific proteins characterized by common structural features, that is, one or more transmembrane domains flanked by cytoplasmic and extracellular portions. Accumulating experimental evidence has suggested that protein-protein interactions at the cytoplasmic region(s) of such transmembrane junctional proteins modulate the extracellular action of the protein which accomplishes homophilic or heterophilic binding to extracellular domains of junctional proteins of neighbouring cells. In this way, a regulatable intercellular seal is created.

Zonula occludens (ZO) proteins, comprising ZO-1, -2, and -3 , are peripheral proteins localizing at junctional sites. $\mathrm{ZO}$ proteins are scaffolding proteins recruiting various types of proteins to the cytoplasmic surface of the junction, thereby contributing to the so called "junctional plaque". ZO proteins have originally been described to localize specifically to tight junctions (TJs) (zonulae occludentes) [1,2]. However, this notion was quickly reevaluated, since these proteins were found to associate with the cadherin-based adherens junctions (AJs) in cells lacking TJs [3]. Moreover, ZO proteins also associate with gap junctions (GJs) by directly interacting with connexins [4-6], which points towards a general role of $\mathrm{ZO}$ proteins in intercellular adhesion and communication.

$\mathrm{ZO}$ proteins carry some domains required for structural organization of intercellular junctions and additional domains capable of functioning in signal transduction pathways. The most prominent function of $\mathrm{ZO}$ proteins at the junctional site is the regulation of claudin polymerization in epithelial cells, which was demonstrated by use of a reverse genetic approach [7].

In recent years, intriguing evidence has accumulated suggesting that $\mathrm{ZO}$ proteins not only exert functions related to structural barrier mechanisms but are also involved in signal transduction and transcriptional modulation.

ZO proteins interact directly with most of the transmembrane proteins localizing at TJs, such as occludin, claudins, JAM (Junctional adhesion molecule), tricellulin, and CAR (coxsackievirus and adenovirus receptor) [8-14] (Figure 1).

Their association with AJs is accomplished through binding to alpha-catenin $[14,15]$ and members of the p120 catenin family [14-17] as well as to the nectin-interacting 


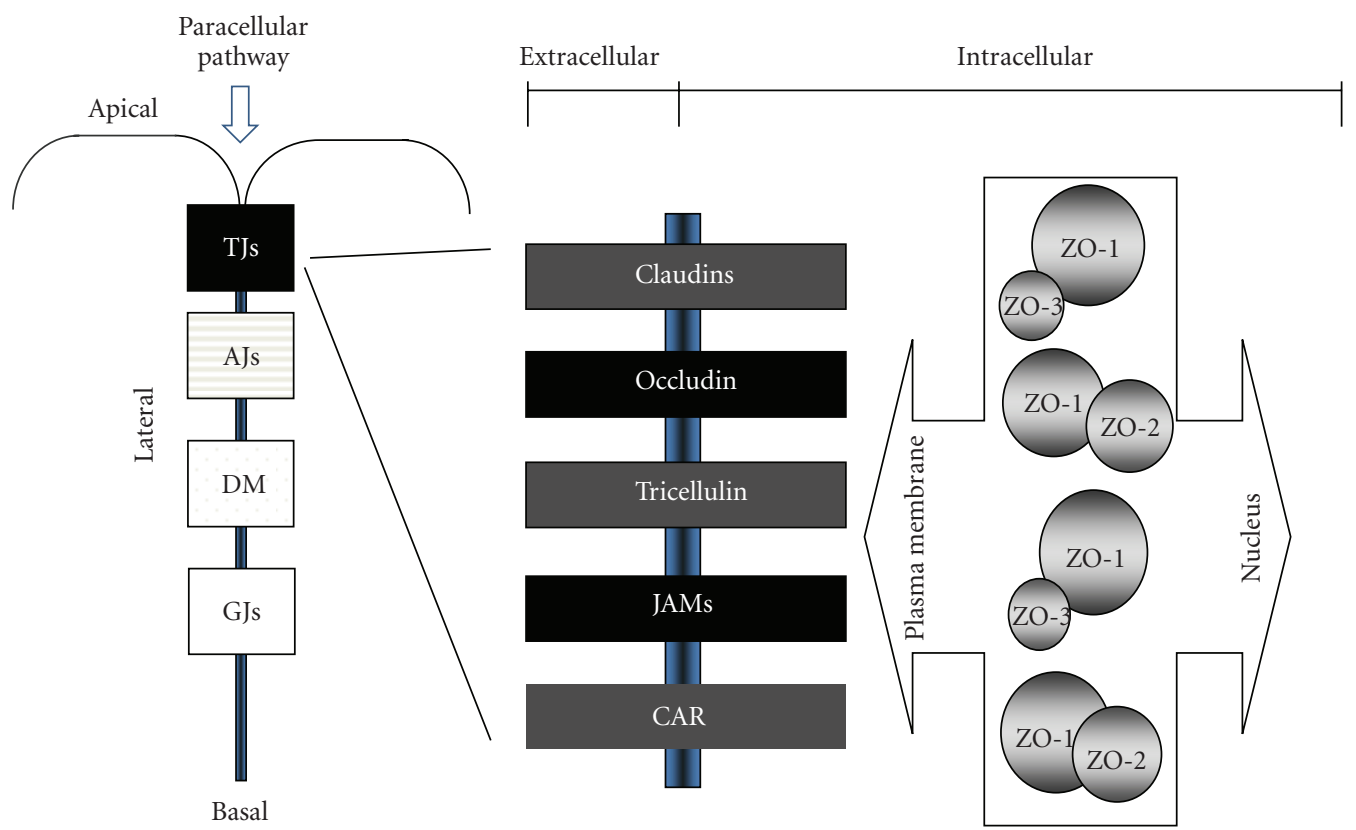

FIGURE 1: Localization of zonula occludens (ZO) proteins at tight junctions (TJs). Transmembrane components of TJs interact at least with one ZO protein. As mentioned in the text, only ZO-1 and ZO-2 localize to the nucleus, while nuclear targeting of ZO-3 has not been observed so far. Already described interactions of ZO proteins with other types of junctions is not included here. TJs: tight junctions; AJs: adherens junctions; DM: desmosomes; GJs: gap junctions; CAR: coxsackievirus and adenovirus receptor.

protein AF-6 (ALL-1 fusion partner at chromosome 6)/ afadin [18]. This somehow reflects the canonical role of $\mathrm{ZO}$ proteins, which is to establish a link between the transmembrane components and the perijunctional cytoskeleton at cell-cell contacts [19-21]. In addition, ZO proteins interact with a series of cytoplasmic proteins, including adapters, signaling molecules and transcriptional regulators [22-27] suggesting a novel function of $\mathrm{ZO}$ proteins, far beyond their role as indispensable structural components at the junction site.

\section{ZO Proteins Are MAGUK Proteins}

$\mathrm{ZO}$ proteins belong to the large family of membraneassociated guanylate kinase (MAGUK) like proteins. The first MAGUK protein dentified was the product of the Drosophila tumor suppressor gene lethal(1)discs-large (dlg). Loss-offunction mutations in dlg lead to the tumorous overgrowth of imaginal discs of Drosophila larvae [28, 29].

MAGUKs are scaffolding proteins which create and maintain multimolecular complexes at distinct subcellular sites, such as the cytoplasmic surface of the plasma membrane [30, 31]. By means of multiple protein binding domains, they bring together cell adhesion molecules, cytoskeletal proteins, receptors, ion channels and additional signaling components. Thereby, protein-protein interaction is accomplished by small modular domains, such as Src-homology3 (SH3) domains, phosphotyrosine-binding domains (PTB), or PDZ domains [30]. In spite of their similar domain structure, MAGUKs are distinctive enough to be classified into seven subfamilies based on domain content and sequence similarity [32].

Junctional MAGUKs belong to the dlg-like and ZO1-like subgroups of MAGUKs. They are characterized by one or more copies of PDZ (PSD-95/discs large/zonula occludens-1) domains, an SH3 (Src Homology 3) domain, and a region homologous to mammalian and yeast cytosolic guanylate kinase (GUK) (from N- to C-terminus). Similar to other MAGUKS, a number of highly variable regions are located between the conserved domains. The best studied variable region is the HOOK domain, a basic hinge region between the $\mathrm{SH} 3$ and GUK domain, involved in regulating ligand binding and oligomerization of MAGUKs $[33,34]$

2.1. PDZ Domain. Although originally identified in metazoans, PDZ domains have been found to be spread through bacteria, fungi and plant lineages as well $[35,36]$. PDZ domains (80-100 amino acid residues) play a key role in cellular signaling. They either form dimers or bind to Cterminal regions of integral membrane and intracellular proteins. PDZ is an acronym, combining the first letters of three proteins which were first discovered to share the domain: The post synaptic density protein (PSD95/SAP90), the Drosophila septate junction protein Discs-large (DlgA), and the epithelial tight junction protein zonula occludens1 (ZO-1). PDZ domains are sometimes referred to as DHR (Dlg homologous region) or GLGF (glycine-leucine-glycinephenylalanine) domains [36]. 
PDZ containing proteins are generally restricted to specific subcellular domains, such as regions of cell-cell contact in epithelial cells, the plasma membrane of red blood cells and lymphocytes, and synaptic and neuromuscular junctions [37]. The majority of PDZ containing proteins is associated with the plasma membrane enabling the creation of higher molecular structures [38]. Such structures are mainly involved in intracellular signaling, cell adhesion, ion transport, and the formation of the paracellular barriers.

2.2. SH3 Domain. The Src homology 3 domain is a small protein domain of about 60 amino acid residues present in a large number of intracellular or membrane-associated proteins [39]. It was first identified as a conserved sequence in the viral adaptor protein c-Crk and the non-catalytic parts of enzymes such as phospholipase and several cytoplasmic tyrosine kinases [39]. SH3 domains are found in proteins that are involved in signaling pathways regulating the cytoskeleton, the Ras protein, and the Src kinase and many others. By binding to proline-rich ligands, these domains play critical roles in a wide variety of biological processes ranging from regulation of enzymes by intramolecular interactions, altering the subcellular localization of components of signaling pathways, and mediating the assembly of large multi-protein complexes [40].

2.3. GUK Domain. GUK (guanylate kinase) domains exhibit sequence similarity to guanylate kinase, which converts GMP to GDP using ATPase as a phosphate donor. Some members of the MAGUK family, such as p55-like and Lin-2-like MAGUKs, have intact GMP binding and ATP-binding sites, while ZO-1-like MAGUKs lack several residues predicted to bind GMP [34, 41]. Interestingly, using phylogenetic analyses and molecular modelling it was demonstrated that the MAGUK GUK domain originated from a catalytically active GK domain and gradually lost its enzymatic characteristics when new subfamilies emerged [32]. Several studies suggest that the GUK domain of MAGUK proteins has evolved as a protein-protein interaction domain. A number of vertebrate GUK domain binding partners, including the microtubuleassociated protein MAP1A [42], the brain-enriched guanylate kinase-associated protein (BEGAIN) [43], and the kinesin-like protein GAKIN [44] have been identified so far. In addition, the MAGUK GUK domain was suggested to interact intramolecularly with the SH3 domain $[41,45]$.

\section{Structural and Functional Properties of ZO Proteins}

The molecular structure and functions of $\mathrm{ZO}$ proteins have extensively been described in a series of comprehensive reviews that appeared during the last couple of years $[19,22$, $24,27,31,46-48]$. Therefore, only a short outline of major characteristics of $\mathrm{ZO}$ proteins is given here.

$\mathrm{ZO}$ proteins carry three $\mathrm{PDZ}$ domains, one $\mathrm{SH} 3$ domain, a GUK domain and a proline-rich region located either at the C-terminus (ZO-1, ZO-2) or between the second and third
PDZ domain (ZO-3) [31]. The variable domains, termed $\mathrm{U}$ (unique) 1 to $\mathrm{U} 6$ are located between the core domains of the ZO proteins (U5 is also referred to as "HOOK" domain) [49]. The SH3-U5-GUK-U6 region of ZO-1 turned out to be of particular importance for TJ assembly and localization [49]. The U5 motif, which is found in several MAGUKs, though without sequence homology, is required for localization of ZO-1 to TJs in vivo and for binding of ZO-1 to occludin in vitro. In contrast, the U6 motif, a short sequence flanking the GUK domain, is unique to $\mathrm{ZO}$ proteins and was found to inhibit binding of $\mathrm{ZO}-1$ to occludin in vitro [49]. Expression of a modified ZO-1, lacking U6, induces ectopic strands consisting of occludin and claudins but lacking most of the cytoplasmic plaque proteins [49]. As in other MAGUKS, the SH3 and GUK domain of ZO-1 form a hairpin loop through intramolecular interaction which could determine the position of the U5 and U6 motifs and thereby modulate the binding capacity of ZO-1 to occludin and to other proteins [49].

The first $\mathrm{ZO}$ protein identified was ZO-1, with a molecular mass of $220 \mathrm{kD}$ [2], which was discovered as an antigen for a monoclonal antibody raised against a junctionenriched fraction from liver tissue. $\mathrm{ZO}-1$ associates with $\mathrm{ZO}-$ 2 , a $160 \mathrm{kD}$ protein $[50,51]$ and the $130 \mathrm{kD}$ protein $\mathrm{ZO}-3$ [52] through binding of their corresponding PDZ-2 domains [53].

Interaction of ZO-1 with the C-termini of claudins was found to be accomplished through PDZ-1 [10], while JAM (Junction adhesion molecule) and occludin are contacted by PDZ 2/3 [9] and a region localized at the SH3-hingeGUK domain, respectively [13, 49] (Figure 2). As mentioned above, the unique motif located in this variable region (termed U5) seems to be indispensable for binding of ZO1 to occludin [49]. Interaction with claudins via their first PDZ domain is a redundant function of all ZO proteins and thus appears to be crucial for the formation and function of TJs. Indeed, Umeda et al. [7] have demonstrated that ZO-1 and $\mathrm{ZO}-2$ are indispensable for determining when and where claudins are polymerized.

$\mathrm{ZO}$ proteins associate with a series of peripheral junctional proteins thereby creating a complex intracellular network (Figure 2). Peripheral junctional proteins include actin-and myosin binding proteins, signalling molecules and transcriptional regulators. In addition, all $\mathrm{ZO}$ proteins interact directly with actin filaments either via their $\mathrm{COOH}$ terminal regions $(\mathrm{ZO}-1, \mathrm{ZO}-2)$ or through a binding domain located in the N-terminal half (ZO-3) which emphasizes their role as cross linkers between TJ strands and the cytoskeleton [54-56]. The importance of the perijunctional actomyosin in $\mathrm{ZO}$ protein-mediated barrier formation was reported recently by Van Itallie et al. [21].

The indirect interaction of $\mathrm{ZO}$ proteins with the cytoskeleton involves several actin-binding proteins including cortactin [57], alpha-catenin [11], protein 4.1R [58], the Ras target AF6/afadin as well as the actin- and myosinbinding proteins cingulin [59] and Shroom [60].

Signalling proteins associating with ZO-proteins include the serin protein kinase ZAK (ZO-1 associated kinase-1) which binds to the $\mathrm{SH} 3$ domain of ZO-1 and phosphorylates 

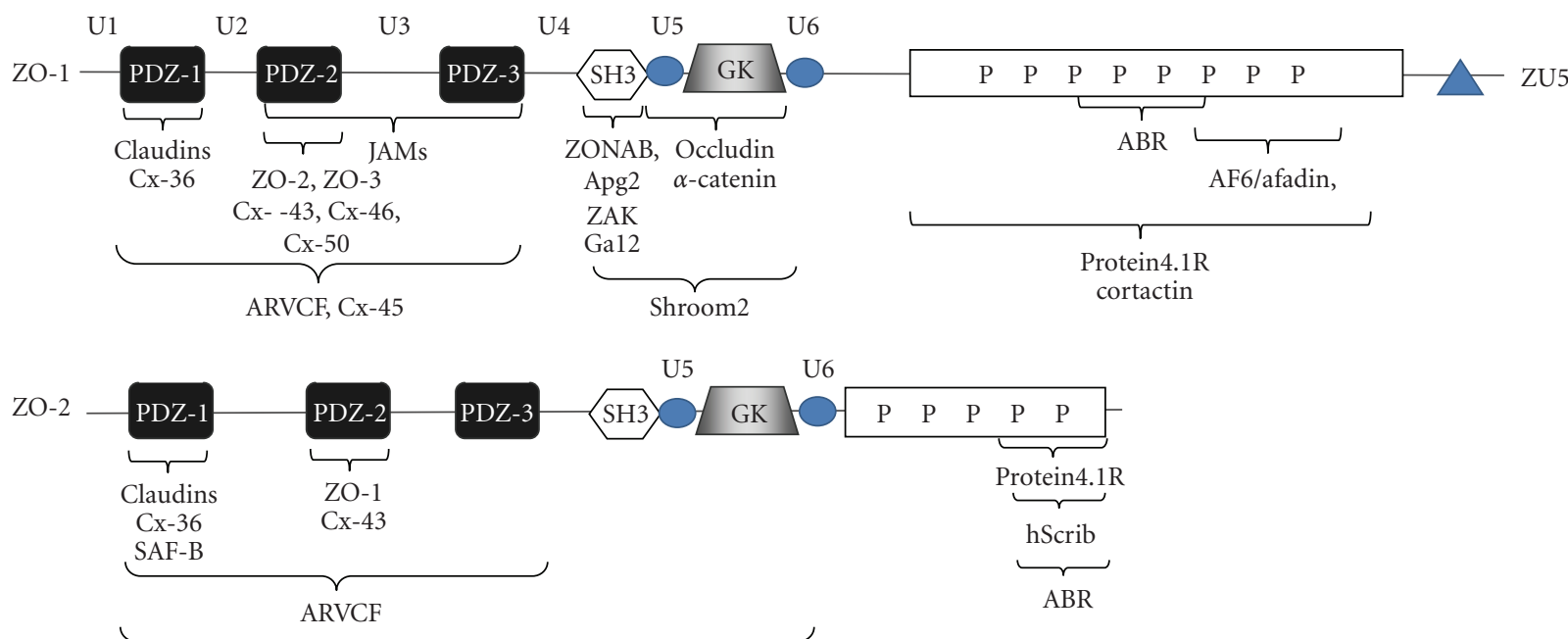

Occludin, $\alpha$-catenin

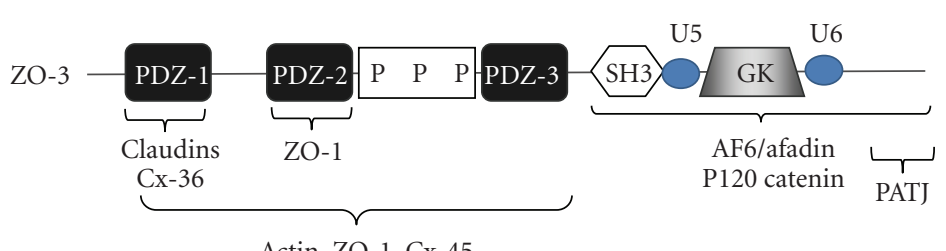

Actin, ZO-1, Cx-45

FIGURE 2: ZO proteins interact with transmembrane proteins and with peripheral cytoplasmic proteins at the junctional site. Details are mentioned in the text. Some proteins interacting with ZO proteins are not included in the figure since their association domain is less well described. These include CAR (coxsackievirus and adenovirus receptor), tricellulin, and cingulin. ABR: actin binding region; AF-6: ALL-1 fusion partner at chromosome 6; Apg-2: (ATP and peptide-binding protein in germ cells)-2; Cx: Connexin; Ga12: G protein $\alpha$ 12 subunit; GUK: Guanylate kinase-like domain; JAM: Junction adhesion molecule; hScrib: human Scribble; PATJ: Protein associated with tight junctions; P-P-P: Proline-rich region; PDZ: Psd95/discs large/zonula occludens-1 domain; SAF-B: Scaffold attachment factor-B; SH3: Src homology3 domain; U1-U6: Unique variable domains; ZAK: ZO-1 associated kinase; ZONAB: ZO-1 associated nucleic acid binding protein; ZU5: Domain present in ZO-1 and Unc5-like netrin receptors.

a region immediately C-terminal to this domain [61] and a G protein $\alpha$ subunit $(\mathrm{G} \alpha 12)$ which also associates directly with the SH3 domain of ZO-1 [62]. Interaction of p120 catenin with a C-teminal domain of $\mathrm{ZO}-3$ provides an additional link to Rho signalling [17, 63]. Signalling at TJs has comprehensively been reviewed recently [64] and is not being dealt with further in this review.

Interaction of ZO-3 with the polarity protein PATJ (protein associated with tight junctions) was suggested to be important for the recruitment of PATJ and its associated proteins to tight junctions [65]. Finally, ZO-2 interacts directly with human Scribble (the human homologue of the Drosophila tumor suppressor Scribble) which was shown to be a substrate of high-risk human papillomavirus E6 oncoproteins for ubiquitin-mediated degradation [66].

The idea of a "dual function" of $\mathrm{ZO}$ proteins has emerged from observations that $\mathrm{ZO}$ proteins interact with proteins involved in cell cycle progression and transcriptional regulation [67]. The nuclear targeting of $\mathrm{ZO}$ proteins and their association with regulatory proteins participating in gene expression will be discussed in a following chapter.

\section{Loss of Function Mutations of ZO Proteins}

In order to gain more insight into the functional significance of $\mathrm{ZO}$ proteins in embryonic development and tissue differentiation, a series of loss-of-function mutations were analysed. Eph4 cells lacking ZO-1 show a retarded recruitment of claudins and occludin to TJs, and delayed barrier establishment [68]. Similar results were obtained by McNeil et al. [69] showing that knockdown of ZO-1 in MDCK cells retarded TJ formation by 3 hours. Interestingly, mature junctions seemed to be unaffected even in the persisting absence of ZO-1. Epithelial cells deficient in both ZO-1 and ZO-2 were well polarized but did not form TJs due to the lack of claudin polymerization [7].

Knockout of ZO-1 was shown to be lethal for mouse embryos around mid gestation [70]. No viable embryos lacking ZO-1 were found beyond E11.5. Disturbed yolk $\mathrm{sac}$ angiogenesis and delayed embryonic growth from E8.5 onwards were the most characteristic features of $\mathrm{ZO}-1^{-{ }^{-}}$ mice. In addition, massive apoptosis in the notochord, in the neural tube area, and in the allantois at E9.5 was described. Interestingly, deficiency of ZO-1 did not exert any 
effects on the localization of ZO-2/ZO-3 at junctional sites but did induce mislocalization of endothelial JAMs in the yolk sac, which might explain the disturbance of vascular development.

Results from ZO-2 targeting experiments are somehow controversial. Knockdown of ZO-2 using siRNA had no discernible effects on TJ structure or function in Eph48 cells, while in MDCK cells, the downregulation of ZO2 yielded a distinct TJ-related phenotype [71]. This was reflected by changes in the gate function of TJs (i.e., increased paracellular permeability and low transepithelial electrical resistance) as well as alterations in the fence function of TJs as evidenced by a non-polarized distribution of E-cadherin. In addition, delayed arrival of ZO-1, occludin and E-cadherin at newly formed junctions following $\mathrm{Ca}^{++}$-switch wasobserved.

Mouse embryos lacking ZO-2 die shortly after implantation due to an arrest in early gastrulation and disturbed mesodermal differentiation. In addition, decreased proliferation at embryonic day 6.5 (E6.5) and increased apoptosis at E7.5 together with elevated paracellular permeability of a low-molecular-weight tracer was observed in $\mathrm{ZO}-2^{-} /^{-}$ embryos [72]. A critical role of ZO-2 for the blood-testis barrier was demonstrated recently by Xu et al. showing that a lack of ZO-2 caused a disturbed blood-testis barrier and lead to reduced fertility of chimeric mice [73].

Neither ZO-3 deficient cells nor mouse embryos lacking ZO-3 showed an apparent phenotype, suggesting that ZO-3 is not an indispensable component of TJs and might well be substituted by one of the other ZO proteins $[72,74]$.

\section{Nuclear Shuttling of ZO Proteins}

Besides their characteristic protein domains $\mathrm{ZO}$ proteins exhibit several nuclear localization (NLS) and nuclear export signals (NES) enabling them to shuttle between the cytoplasm and the nucleus [75-78].

A first indication that a member of the $\mathrm{ZO}$ proteins localizes to the nucleus came from Gottardi et al., [79] showing that ZO-1 targets for the nucleus of subconfluent epithelial cells before maturation of TJs. Gonzalez-Mariscal and her group demonstrated that the nuclear localization of ZO-2 is particularly dependent on the state of cell cell contacts in epithelial monolayers [76]. Particularly in sparse cultures, $\mathrm{ZO}-2$ was found to localize at the nucleus but gradually exits the nucleus in a leptomycin-sensitive way as soon as the monolayer reaches confluence. Transient nuclear expression of ZO-2 in cerebral endothelial cells and kidney epithelial cells was also observed by Traweger et al. [78]. ZO-2 was found to colocalize partially with the pre-mRNA splicing factor SC-35 and to coprecipitate with laminB1 and actin from nuclei of sparse cultures [76].

Following heat shock and chemical insult increased nuclear accumulation of ZO-2 was visible in epithelial and endothelial cells [78]. Further, nuclear localization could be induced by impairing cell-cell contacts by mechanical injury (wounding) [76]. This suggests that nuclear accumulation of $\mathrm{ZO}-2$ is a general response of epithelial and endothelial cells to environmental or mechanical stress.

\section{Nuclear Actions of ZO Proteins}

Although the dual localization (cytoplasmic/nuclear) of ZO proteins is well documented, the biological significance of their nuclear targeting has long remained elusive. ZO proteins interact with nuclear proteins as well as with dual residency (cytoplasmic/nuclear) proteins (Figures 3(a) and $3(\mathrm{~b})$ ) suggested to be involved in cell growth and proliferation.

By using a yeast-based Two Hybrid screen and coimmunoprecipitation, it was shown that nuclear ZO-2 interacts directly with the hnRNP protein SAF-B (scaffold attachment factor-B) via its PDZ-1 domain [78]. SAF$\mathrm{B} / \mathrm{HET}$ (Hsp27-ERE-TATA-binding protein) is a component of chromatin and is expressed in all tissues investigated so far. Originally, SAF-B/HET has been described as one of the abundant nuclear proteins that function in chromatin structure by interacting with scaffold or matrix attachment DNA elements (S/MAR elements). In many cases, these elements co-map with boundaries of actively transcribed domains and have therefore been considered to exert regulatory effects on adjacent genes [80]. SAF-B/HET was shown to be highly concentrated in nuclear speckles colocalizing with SC-35 and to directly interact with various splicing factors and RNA polymerase II [81]. In addition, SAF-B/HET acts as a co-repressor of estrogen receptor alpha and SAF$\mathrm{B} / \mathrm{HET}$ levels were found to be inversely correlated with cell proliferation of breast cancer cells [82]. SAF-B/HET is a suppressor of the small heat shock protein 27 (hsp27) which enhances growth and proliferation of breast cancer cells and turned out to be a bad prognostic marker in certain subsets of breast cancer patients in breast carcinoma cells [83].

Further evidence to suggest direct involvement of ZO-2 in cell growth and proliferation came from Huerta et al. [84] demonstrating that ZO-2 modulates the expression of cyclin D1 (CD1) through interaction with the transcription factor Myc and subsequent binding to an enhancer box element of the $\mathrm{CD} 1$ promoter. In this way, ZO-2 downregulates transcription of $\mathrm{CD} 1$ and, in due course, suppresses proliferation of cultured epithelial cells. In addition, ZO-2 downregulates protein synthesis of CD- 1 and increases its degradation at the proteasome complex [85].

Convincing experimental evidence to suggest the critical involvement of $\mathrm{ZO}$ proteins in epithelial cell proliferation came from Balda et al. [86, 87] and Sourisseau et al. [88] showing that ZO-1 interacts with the Y-box transcription factor ZONAB (ZO-1 associated nucleic acid binding protein), also referred to as DbpA/Msy3 (DNA binding proteinA/Mouse $\mathrm{Y}$ box protein3), which in turn binds to promoter regions of CD1 and PCNA (proliferating cell nuclear antigen), an eukaryotic DNA replication factor, thereby increasing their transcription. ZONAB is a dual residency protein localizing at TJs and/or in the nucleus, depending on the cells' proliferative state and on the amount of ZO-1 present at cell-cell contact sites. In confluent epithelial monolayers, ZONAB is bound to junctional ZO1. If $Z \mathrm{ZO}-1$ is absent from junctional sites, ZONAB shuttles to the nucleus while overexpression of junctional ZO-1 causes 


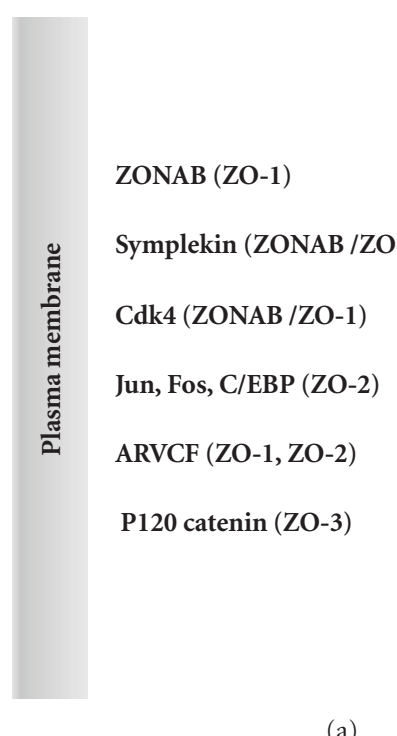

(a)

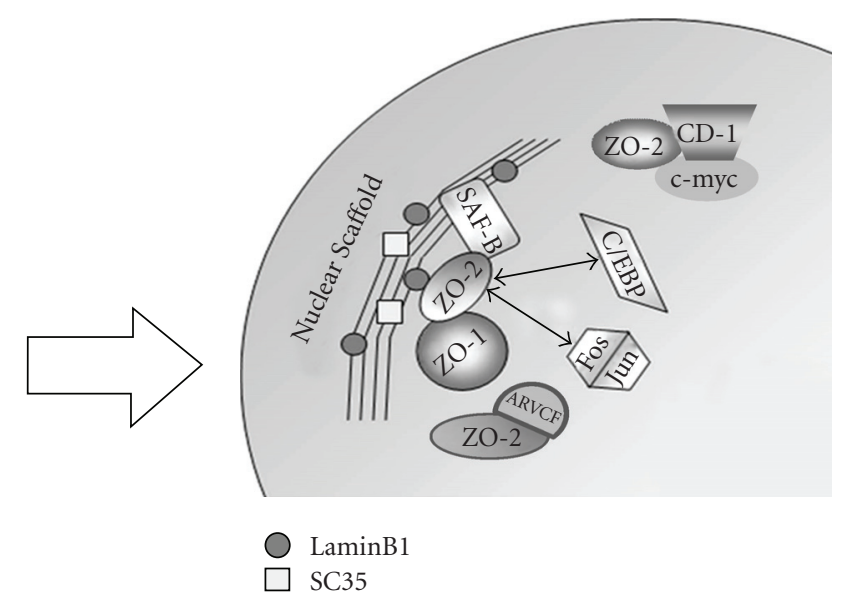

(b)

FIGURE 3: (a) Summary of "dual residency proteins" (locating at the plasma membrane and at the nucleus) associating with ZO-proteins at the junctional site. (b) Nuclear interactions of ZO proteins. ZONAB: ZO-1 associated nucleic acid binding protein; Cdk-4: Cyclin-dependent kinase-4; ARVCF: Armadillo repeat gene deleted in velo-cardio-facial syndrome; SC35: Splicing factor 35.

a redistribution of $Z O N A B$ from the nucleus to the cytoplasm. Another way, how ZONAB regulates epithelial cell proliferation and cell cycle progression is through association with the cyclin-dependent kinase-4 (Cdk4) which interacts and colocalizes with ZONAB at TJs. In this way, Cdk4 is prevented from entering the nucleus and participating in cell cycle progression [86].

The small heat shock protein Apg-2 was shown to regulate $\mathrm{ZONAB}$ function by competing for binding to the SH3 domain of ZO-1 [89]

In addition, ZONAB forms a stable complex with symplekin, a ubiquitous protein involved in mRNA processing [90]. Similar to ZONAB and Cdk4, symplekin is a dual residency protein which usually accumulates at cell nuclei but also associates with TJs in polarized epithelial cells [90]. Interaction of ZONAB with symplekin modulates the transcriptional activity of ZONAB as evidenced by alterations in CD1 expression [91].

A direct interaction of ZO-2 with Jun, Fos and C/EBP (CCAAT/enhancer binding protein) was found to occur not only in the nucleus but also at the plasma membrane [92]. Using reporter gene assays, ZO-2 was demonstrated to suppress gene transcription by binding to the AP-1 transcription factor protein complex [92].

Further, ZO-1 and ZO-2 interact with the dual residency protein ARVCF (Armadillo repeat gene deleted in velo-cardio-facial syndrome) [16], a member of the p120 catenin family localizing at cadherin-based cell-cell contacts in confluent epithelial cells. Upon disruption of cell-cell adhesion, ARVCF is partially translocated to the nucleus by associating with a PDZ domain of ZO-2. In addition, a Cterminal region of ZO-3 was shown to interact directly with p120 catenin, which regulates cadherin-based cell adhesion and junctional stabilization through Rho signaling [63]. p120 catenin was found to undergo nucleo-cytoplasmic shuttling and to regulate gene expression by associating with the methylation-dependent transcriptional repressor Kaiso [93].

Experimentally induced nuclear accumulation of ZO2 in cerebral endothelial cells led to the elevation of pyruvate kinase M2 (M2PK) protein levels [94]. Although experimental evidence is still missing, it cannot be excluded that this effect was elicited by the excessive targeting of nuclear ZO-2 to the estrogen receptor-binding domain of SAF-B. M2PK is an isozyme of pyruvate kinase particularly expressed in proliferating cells, such as embryonic stem cells and carcinoma cells. A recent report has demonstrated that $\mathrm{M} 2 \mathrm{PK}$ interacts and cooperates with the POU domain transcription factor Oct-4 which is critically involved in maintaining the self-renewal capacity of embryonic stem cells [95]. Although there is a general consensus concerning the suppressive action of ZO-2 on cell proliferation, it appears that the ratio between the amount of $\mathrm{ZO}-2$ localizing at TJs and the amount of nuclear ZO-2 adds an additional variable in the control of epithelial cell proliferation and differentiation.

While the nuclear targeting of ZO-1 has well been described, its nuclear functions have remained unclear. Based on all experimental evidence so far, it may be concluded that the nuclear localization of $\mathrm{ZO}-1$ is inversely related to the extent and/or maturity of cell-cell contacts [79].

\section{A Role for ZO Proteins in Tumor Growth}

Some proteins of the MAGUK family behave as tumor suppressors. The homology of ZO proteins with the Drosophila 
tumour suppressor protein $d \lg A$ provided a first clue towards a yet undefined role of ZO proteins in epithelial cancer development and/or progression. Dlg proteins with mutations in the PDZ and SH3 domains cause neoplastic overgrowth of larval imaginal disc epithelial cells [28]. The Drosophila orthologue of ZO-1, Tamou/Polychaetoid, has been implicated in a signaling pathway which activates the expression of the helix-loop-helix repressor gene emc (extramacrochaetae). Mutations in Tamou/Polychaetoid reduce the expression of emc, which causes enlargement of a proneural cell cluster resulting in extra mechanosensory organs in the fly [96].

$\mathrm{ZO}$ proteins are delocalized or down-regulated in several types of carcinomas [97]. Further, ZO-1 mutants encoding only the $\mathrm{N}$ terminus including the $\mathrm{PDZ}$ domains of $\mathrm{ZO}$ 1 appeared delocalized in the cytoplasm of MDCK cells and induced a dramatic loss of the epithelial phenotype of MDCK accompanied by repression of epithelial and induction of mesenchymal marker genes [98]. Similar results were obtained by Wittchen et al showing that expression of exogenous mutated ZO-3 constructs carrying only the amino terminal half of $\mathrm{ZO}-3$ led to a significant delay in the formation of TJs and AJs and to mislocalization of $\mathrm{ZO}$ proteins and occludin [99].

Epithelial cancers are often related to mutations in the small GTPase Ras, which mediates cellular signal transduction regulating cell growth and proliferation [100]. The peripheral PDZ domain protein AF-6/afadin localizes at AJ and TJs by directly associating with nectin and JAM $[9,101]$. AF-6 was shown to be targeted by Ras and the Ras-like GTPase Rap-1 [102, 103]. In polarized epithelial cells, AF-6/afadin colocalizes with ZO-1 at TJs, and ZO1 interacts with the Ras-binding domain of AF-6/afadin. Overexpression of activated Ras in Rat 1 cells resulted in the perturbation of cell-cell contacts, demonstrating a critical interplay of Ras, AF-6/afadin and ZO-1 at intercellular junctions [104].

Junctional proteins carrying PDZ domains were found to be targeted and degraded by various tumorigenic viruses [105]. Thereby; PDZ binding motifs located in the viral protein are used to interact with PDZ domains of the targeted junctional protein. For example, a conserved 4-amino-acid PDZ binding motif is present at the carboxy termini of highrisk human papillomavirus (HPV) E6 proteins [106]. Similarly, adenovirus (Ad) type 9 causing exclusively estrogendependent mammary tumors in experimental animals contains a PDZ domain-binding motif required to induce both cellular transformation in vitro and tumorigenesis in vivo. The PDZ domain of Ad9 mediates interaction with Dlg1, PATJ and ZO-2 which promotes disruption and loss of cell polarity of the infected cells [107].

\section{Concluding Remarks}

Due to their homology with the tumor suppressor proten dlgA, zonula occludens proteins have been considered to play a role in cell growth and proliferation. Since the discovery of the first TJ-associated MAGUK, ZO-1, the importance of peripheral junctional proteins has become increasingly recognized. It was considered a major breakthrough when it was demonstrated that $\mathrm{ZO}$ proteins not only exert a scaffolding function at the junctional site but are also involved in intracellular signaling and gene expression. The nuclear targeting of ZO-1 and ZO-2 has focused much interest on the nuclear function of $\mathrm{ZO}$ proteins. To date, convincing experimental evidence suggests that $\mathrm{ZO}$ proteins are capable of associating with regulatory molecules (adapter proteins, signaling molecules, growth factors) thereby modulating the cell's progress through the cell cycle. Now, future work must concentrate on several aspects, including (i) the elucidation of extra- and intracellular signals which trigger the nuclear targeting of $\mathrm{ZO}$ proteins, (ii) the identification of additional genes the expression of which is up- or downregulated by the nuclear presence of $\mathrm{ZO}$ proteins, and (iii) the role of $\mathrm{ZO}$ proteins in virus-induced cancer.

\section{References}

[1] J. M. Anerson, B. R. Stevenson, L. A. Jesaitis, D. A. Goodenough, and M. S. Mooseker, "Characterization of ZO1 , a protein component of the tight junction from mouse liver and Madin-Darby canine kidney cells," Journal of Cell Biology, vol. 106, no. 4, pp. 1141-1149, 1988.

[2] B. R. Stevenson, J. D. Siliciano, and M. S. Mooseker, "Identification of ZO-1: a high molecular weight polypeptide associated with the tight junction (Zonula Occludens) in a variety of epithelia," Journal of Cell Biology, vol. 103, no. 3, pp. 755-766, 1986.

[3] A. G. Howarth, M. R. Hughes, and B. R. Stevenson, "Detection of the tight junction-associated protein $\mathrm{ZO}-1$ in astrocytes and other nonepithelial cell types," American Journal of Physiology, vol. 262, no. 2, pp. C461-C469, 1992.

[4] P. J. Kausalya, M. Reichert, and W. Hunziker, "Connexin45 directly binds to ZO-1 and localizes to the tight junction region in epithelial MDCK cells," FEBS Letters, vol. 505, no. 1, pp. 92-96, 2001.

[5] X. Li, C. Olson, S. Lu, and J. I. Nagy, "Association of connexin36 with zonula occludens- 1 in HeLa cells, $\beta$ TC-3 cells, pancreas, and adrenal gland," Histochemistry and Cell Biology, vol. 122, no. 5, pp. 485-498, 2004.

[6] D. Singh, J. L. Solan, S. M. Taffet, R. Javier, and P. D. Lampe, "Connexin 43 interacts with zona occludens-1 and -2 proteins in a cell cycle stage-specific manner," Journal of Biological Chemistry, vol. 280, no. 34, pp. 30416-30421, 2005.

[7] K. Umeda, J. Ikenouchi, S. Katahira-Tayama, et al., "ZO1 and ZO-2 independently determine where claudins are polymerized in tight-junction strand formation," Cell, vol. 126, no. 4, pp. 741-754, 2006.

[8] C. J. Cohen, J. Gaetz, T. Ohman, and J. M. Bergelson, "Multiple regions within the coxsackievirus and adenovirus receptor cytoplasmic domain are required for basolateral sorting," Journal of Biological Chemistry, vol. 276, no. 27, pp. 25392-25398, 2001.

[9] K. Ebnet, C. U. Schulz, M.-K. Meyer Zu Brickwedde, G. G. Pendl, and D. Vestweber, "Junctional adhesion molecule interacts with the PDZ domain-containing proteins AF-6 and ZO-1," Journal of Biological Chemistry, vol. 275, no. 36, pp. 27979-27988, 2000. 
[10] M. Itoh, M. Furuse, K. Morita, K. Kubota, M. Saitou, and S. Tsukita, "Direct binding of three tight junction-associated MAGUKs, ZO-1, ZO-2, and ZO-3, with the $\mathrm{COOH}$ termini of claudins," Journal of Cell Biology, vol. 147, no. 6, pp. 1351$1363,1999$.

[11] S. L. Muller, M. Portwich, A. Schmidt, et al., "The tight junction protein occludin and the adherens junction protein $\alpha$-catenin share a common interaction mechanism with $\mathrm{ZO}$ 1," Journal of Biological Chemistry, vol. 280, no. 5, pp. 37473756, 2005.

[12] S. Riazuddin, Z. M. Ahmed, A. S. Fanning, et al., "Tricellulin is a tight-junction protein necessary for hearing," American Journal of Human Genetics, vol. 79, no. 6, pp. 1040-1051, 2006.

[13] A. Schmidt, D. I. Utepbergenov, S. L. Mueller, et al., "Occludin binds to the SH3-hinge-GuK unit of zonula occludens protein 1: potential mechanism of tight junction regulation," Cellular and Molecular Life Sciences, vol. 61, no. 11, pp. 1354-1365, 2004.

[14] M. Itoh, K. Morita, and S. Tsukita, "Characterization of ZO-2 as a MAGUK family member associated with tight as well as adherens junctions with a binding affinity to occludin and $\alpha$ catenin," Journal of Biological Chemistry, vol. 274, no. 9, pp. 5981-5986, 1999.

[15] M. Itoh, A. Nagafuchi, S. Moroi, and S. Tsukita, "Involvement of ZO-1 in cadherin-based cell adhesion through its direct binding to $\alpha$ catenin and actin filaments," Journal of Cell Biology, vol. 138, no. 1, pp. 181-192, 1997.

[16] P. J. Kausalya, D. C. Y. Phua, and W. Hunziker, "Association of ARVCF with zonula occludens (ZO)-1 and ZO-2: binding to PDZ-domain proteins and cell-cell adhesion regulate plasma membrane and nuclear localization of ARVCF," Molecular Biology of the Cell, vol. 15, no. 12, pp. 5503-5515, 2004.

[17] E. S. Wittchen, J. Haskins, and B. R. Stevenson, "NZO-3 expression causes global changes to actin cytoskeleton in Madin-Darby canine kidney cells: linking a tight junction protein to Rho GTPases," Molecular Biology of the Cell, vol. 14, no. 5, pp. 1757-1768, 2003.

[18] Y. Takai and H. Nakanishi, "Nectin and afadin: novel organizers of intracellular junctions," Journal of Cell Science, vol. 116, no. 1, pp. 17-27, 2003.

[19] A. S. Fanning and J. M. Anderson, "Zonula occludens-1 and 2 are cytosolic scaffolds that regulate the assembly of cellular junctions," Annals of the New York Academy of Sciences, vol. 1165, pp. 113-120, 2009.

[20] J. Miyoshi and Y. Takai, "Structural and functional associations of apical junctions with cytoskeleton," Biochimica et Biophysica Acta, vol. 1778, no. 3, pp. 670-691, 2008.

[21] C. M. Van Itallie, A. S. Fanning, A. Bridges, and J. M. Anderson, "ZO-1 stabilizes the tight junction solute barrier through coupling to the perijunctional cytoskeleton," Molecular Biology of the Cell, vol. 20, no. 17, pp. 3930-3940, 2009.

[22] M. S. Balda and K. Matter, "Tight junctions at a glance," Journal of Cell Science, vol. 121, no. 22, pp. 3677-3682, 2008.

[23] M. S. Balda and K. Matter, "Tight junctions and the regulation of gene expression," Biochimica et Biophysica Acta, vol. 1788 , no. 4 , pp. 761-767, 2009.

[24] F. D'Atri and S. Citi, "Molecular complexity of vertebrate tight junctions (review)," Molecular Membrane Biology, vol. 19, no. 2, pp. 103-112, 2002.

[25] L. Guillemot, S. Paschoud, P. Pulimeno, A. Foglia, and S. Citi, "The cytoplasmic plaque of tight junctions: a scaffolding and signalling center," Biochimica et Biophysica Acta, vol. 1778, no. 3, pp. 601-613, 2008.
[26] K. Matter and M. S. Balda, "Signalling to and from tight junctions," Nature Reviews Molecular Cell Biology, vol. 4, no. 3, pp. 225-236, 2003.

[27] L. Paris, L. Tonutti, C. Vannini, and G. Bazzoni, "Structural organization of the tight junctions," Biochimica et Biophysica Acta, vol. 1778, no. 3, pp. 646-659, 2008.

[28] E. Willott, M. S. Balda, A. S. Fanning, B. Jameson, C. Van Itallie, and J. M. Anderson, "The tight junction protein ZO-1 is homologous to the Drosophila discs- large tumor suppressor protein of septate junctions," Proceedings of the National Academy of Sciences of the United States of America, vol. 90, no. 16, pp. 7834-7838, 1993.

[29] D. F. Woods and P. J. Bryant, "The discs-large tumor suppressor gene of Drosophila encodes a guanylate kinase homolog localized at septate junctions," Cell, vol. 66, no. 3, pp. 451-464, 1991.

[30] S. D. Dimitratos, D. F. Woods, D. G. Stathakis, and P. J. Bryant, "Signaling pathways are focused at specialized regions of the plasma membrane by scaffolding proteins of the MAGUK family," BioEssays, vol. 21, no. 11, pp. 912-921, 1999.

[31] L. González-Mariscal, A. Betanzos, and A. Avila-Flores, "MAGUK proteins: structure and role in the tight junction," Seminars in Cell and Developmental Biology, vol. 11, no. 4, pp. 315-324, 2000.

[32] A. J. W. Te Velthuis, J. F. Admiraal, and C. P. Bagowski, "Molecular evolution of the MAGUK family in metazoan genomes," BMC Evolutionary Biology, vol. 7, 2007.

[33] A. W. McGee, S. R. Dakoji, O. Olsen, D. S. Bredt, W. A. Lim, and K. E. Prehoda, "Structure of the SH3-guanylate kinase module from PSD-95 suggests a mechanism for regulated assembly of MAGUK scaffolding proteins," Molecular Cell, vol. 8, no. 6, pp. 1291-1301, 2001.

[34] G. A. Tavares, E. H. Panepucci, and A. T. Brunger, "Structural characterization of the intramolecular interaction between the SH3 and guanylate kinase domains of PSD-95," Molecular Cell, vol. 8, no. 6, pp. 1313-1325, 2001.

[35] L. Funke, S. Dakoji, and D. S. Bredt, "Membrane-associated guanylate kinases regulate adhesion and plasticity at cell junctions," Annual Review of Biochemistry, vol. 74, pp. 219245, 2005.

[36] F. Jelen, A. Oleksy, K. Smietana, and J. Otlewski, "PDZ domains-common players in the cell signaling," Acta Biochimica Polonica, vol. 50, no. 4, pp. 985-1017, 2003.

[37] B. Z. Harris and W. A. Lim, "Mechanisma and role of PDZ domains in signaling complex assembly," Journal of Cell Science, vol. 114, no. 18, pp. 3219-3231, 2001.

[38] A. S. Fanning and J. M. Anderson, "Protein modules as organizers of membrane structure," Current Opinion in Cell Biology, vol. 11, no. 4, pp. 432-439, 1999.

[39] T. Pawson and J. Schlessinger, "SH2 and SH3 domains," Current Biology, vol. 3, no. 7, pp. 434-442, 1993.

[40] B. J. Mayer, "SH3 domains: complexity in moderation," Journal of Cell Science, vol. 114, no. 7, pp. 1253-1263, 2001.

[41] A. W. McGee and D. S. Bredt, "Identification of an intramolecular interaction between the $\mathrm{SH} 3$ and guanylate kinase domains of PSD-95," Journal of Biological Chemistry, vol. 274, no. 25, pp. 17431-17436, 1999.

[42] J. E. Brenman, J. R. Topinka, E. C. Cooper, et al., "Localization of postsynaptic density-93 to dendritic microtubules and interaction with microtubule-associated protein 1A," Journal of Neuroscience, vol. 18, no. 21, pp. 8805-8813, 1998. 
[43] M. Deguchi, Y. Hata, M. Takeuchi, et al., "BEGAIN (brainenriched guanylate kinase-associated protein), a novel neuronal PSD-95/SAP90-binding protein," Journal of Biological Chemistry, vol. 273, no. 41, pp. 26269-26272, 1998.

[44] T. Hanada, L. Lin, E. V. Tibaldi, E. L. Reinherz, and A. H. Chishti, "GAKIN, a novel kinesin-like protein associates with the human homologue of the Drosophila Discs large tumor suppressor in T lymphocytes," Journal of Biological Chemistry, vol. 275, no. 37, pp. 28774-28784, 2000.

[45] H. Shin, Y.-P. Hsueh, F.-C. Yang, E. Kim, and M. Sheng, "An intramolecular interaction between Src homology 3 domain and guanylate kinase-like domain required for channel clustering by postsynaptic density-95/SAP90," Journal of Neuroscience, vol. 20, no. 10, pp. 3580-3587, 2000.

[46] S. Aijaz, M. S. Balda, and K. Matter, "Tight junctions: molecular architecture and function," International Review of Cytology, vol. 248, pp. 261-298, 2006.

[47] L. González-Mariscal, A. Betanzos, P. Nava, and B. E. Jaramillo, "Tight junction proteins," Progress in Biophysics and Molecular Biology, vol. 81, no. 1, pp. 1-44, 2003.

[48] S. Tsukita, M. Furuse, and M. Itoh, "Multifunctional strands in tight junctions," Nature Reviews Molecular Cell Biology, vol. 2, no. 4, pp. 285-293, 2001.

[49] A. S. Fanning, B. P. Little, C. Rahner, D. Utepbergenov, Z. Walther, and J. M. Anderson, "The unique-5 and -6 motifs of ZO-1 regulate tight junction strand localization and scaffolding properties," Molecular Biology of the Cell, vol. 18, no. 3, pp. 721-731, 2007.

[50] B. Gumbiner, T. Lowenkopf, and D. Apatira, "Identification of a $160-\mathrm{kDa}$ polypeptide that binds to the tight junction protein ZO-1," Proceedings of the National Academy of Sciences of the United States of America, vol. 88, no. 8, pp. 3460-3464, 1991.

[51] L. A. Jesaitis and D. A. Goodenough, "Molecular characterization and tissue distribution of $\mathrm{ZO}-2$, a tight junction protein homologous to ZO-1 and the Drosophila discs-large tumor suppressor protein," Journal of Cell Biology, vol. 124, no. 6, pp. 949-961, 1994.

[52] J. Haskins, L. Gu, E. S. Wittchen, J. Hibbard, and B. R. Stevenson, "ZO-3, a novel member of the MAGUK protein family found at the tight junction, interacts with $\mathrm{ZO}-1$ and occludin," Journal of Cell Biology, vol. 141, no. 1, pp. 199-208, 1998.

[53] D. I. Utepbergenov, A. S. Fanning, and J. M. Anderson, "Dimerization of the scaffolding protein ZO-1 through the second PDZ domain," Journal of Biological Chemistry, vol. 281, no. 34, pp. 24671-24677, 2006.

[54] A. S. Fanning, B. J. Jameson, L. A. Jesaitis, and J. M. Anderson, "The tight junction protein ZO-1 establishes a link between the transmembrane protein occludin and the actin cytoskeleton," Journal of Biological Chemistry, vol. 273, no. 45, pp. 29745-29753, 1998.

[55] A. S. Fanning, T. Y. Ma, and J. M. Anderson, "Isolation and functional characterization of the actin binding region in the tight junction protein ZO-1," The FASEB Journal, vol. 16, no. 13 , pp. 1835-1837, 2002.

[56] E. S. Wittchen, J. Haskins, and B. R. Stevenson, "Protein interactions at the tight junction. Actin has multiple binding partners, and ZO-1 forms independent complexes with ZO-2 and ZO-3," Journal of Biological Chemistry, vol. 274, no. 49, pp. 35179-35185, 1999.
[57] T. Katsube, M. Takahisa, R. Ueda, N. Hashimoto, M. Kobayashi, and S. Togashi, "Cortactin associates with the cellcell junction protein ZO-1 in both Drosophila and mouse," Journal of Biological Chemistry, vol. 273, no. 45, pp. 2967229677, 1998.

[58] S. N. Mattagajasingh, S.-C. Huang, J. S. Hartenstein, and E. J. Benz Jr., "Characterization of the interaction between protein 4.1R and ZO-2: a possible link between the tight junction and the actin cytoskeleton," Journal of Biological Chemistry, vol. 275, no. 39, pp. 30573-30585, 2000.

[59] F. D'Atri, F. Nadalutti, and S. Citi, "Evidence for a functional interaction between cingulin and ZO-1 in cultured cells," Journal of Biological Chemistry, vol. 277, no. 31, pp. 2775727764, 2002.

[60] R. Etournay, I. Zwaenepoel, I. Perfettini, P. Legrain, C. Petit, and A. El-Amraoui, "Shroom2, a myosin-VIIa- and actin-binding protein, directly interacts with ZO-1 at tight junctions," Journal of Cell Science, vol. 120, no. 16, pp. 28382850, 2007.

[61] M. S. Balda, J. M. Anderson, and K. Matter, "The SH3 domain of the tight junction protein $\mathrm{ZO}-1$ binds to a serine protein kinase that phosphorylates a region C-terminal to this domain," FEBS Letters, vol. 399, no. 3, pp. 326-332, 1996.

[62] T. N. Meyer, C. Schwesinger, and B. M. Denker, "Zonula occludens-1 is a scaffolding protein for signaling molecules: $\mathrm{G} \alpha_{12}$ directly binds to the Src homology 3 domain and regulates paracellular permeability in epithelial cells," Journal of Biological Chemistry, vol. 277, no. 28, pp. 24855-24858, 2002.

[63] P. Z. Anastasiadis and A. B. Reynolds, "Regulation of Rho GTPases by p120-catenin," Current Opinion in Cell Biology, vol. 13, no. 5, pp. 604-610, 2001.

[64] L. González-Mariscal, R. Tapia, and D. Chamorro, "Crosstalk of tight junction components with signaling pathways," Biochimica et Biophysica Acta, vol. 1778, no. 3, pp. 729-756, 2008.

[65] M. H. Roh, C.-J. Liu, S. Laurinec, and B. Margolis, "The carboxyl terminus of zona occludens- 3 binds and recruits a mammalian homologue of discs lost to tight junctions," Journal of Biological Chemistry, vol. 277, no. 30, pp. 2750127509, 2002.

[66] J.-Y. Metais, C. Navarro, M.-J. Santoni, S. Audebert, and J.-P. Borg, "hScrib interacts with ZO-2 at the cell-cell junctions of epithelial cells," FEBS Letters, vol. 579, no. 17, pp. 3725-3730, 2005.

[67] K. Matter and M. S. Balda, "Epithelial tight junctions, gene expression and nucleo-junctional interplay," Journal of Cell Science, vol. 120, no. 9, pp. 1505-1511, 2007.

[68] K. Umeda, T. Matsui, M. Nakayama, et al., "Establishment and characterization of cultured epithelial cells lacking expression of ZO-1," Journal of Biological Chemistry, vol. 279, no. 43, pp. 44785-44794, 2004.

[69] E. McNeil, C. T. Capaldo, and I. G. Macara, "Zonula occludens-1 function in the assembly of tight junctions in Madin-Darby canine kidney epithelial cells," Molecular Biology of the Cell, vol. 17, no. 4, pp. 1922-1932, 2006.

[70] T. Katsuno, K. Umeda, T. Matsui, et al., "Deficiency of zonula occludens-1 causes embryonic lethal phenotype associated with defected yolk sac angiogenesis and apoptosis of embryonic cells," Molecular Biology of the Cell, vol. 19, no. 6, pp. 2465-2475, 2008. 
[71] S. Hernandez, B. Chavez Munguia, and L. GonzálezMariscal, "ZO-2 silencing in epithelial cells perturbs the gate and fence function of tight junctions and leads to an atypical monolayer architecture," Experimental Cell Research, vol. 313, no. 8, pp. 1533-1547, 2007.

[72] J. Xu, P. J. Kausalya, D. C. Y. Phua, S. M. Ali, Z. Hossain, and W. Hunziker, "Early embryonic lethality of mice lacking $\mathrm{ZO}-2$, but not $\mathrm{ZO}-3$, reveals critical and nonredundant roles for individual zonula occludens proteins in mammalian development," Molecular and Cellular Biology, vol. 28, no. 5, pp. 1669-1678, 2008.

[73] J. Xu, F. Anuar, S. M. Ali, Y. N. Mei, D. C. Y. Phua, and W. Hunziker, "Zona occludens-2 is critical for blood-testis barrier integrity and male fertility," Molecular Biology of the Cell, vol. 20, no. 20, pp. 4268-4277, 2009.

[74] M. Adachi, A. Inoko, M. Hata, et al., "Normal establishment of epithelial tight junctions in mice and cultured cells lacking expression of ZO-3, a tight-junction MAGUK protein," Molecular and Cellular Biology, vol. 26, no. 23, pp. 9003-9015, 2006.

[75] E. López-Bayghen, B. E. Jaramillo, M. Huerta, A. Betanzos, and L. González-Mariscal, "TJ proteins that make round trips to the nucleus," in Tight Junctions, pp. 1-25, edited by Eurekah.com, 2005.

[76] S. Islas, J. Vega, L. Ponce, and L. González-Mariscal, "Nuclear localization of the tight junction protein $\mathrm{ZO}-2$ in epithelial cells," Experimental Cell Research, vol. 274, no. 1, pp. 138$148,2002$.

[77] B. E. Jaramillo, A. Ponce, J. Moreno, et al., "Characterization of the tight junction protein ZO-2 localized at the nucleus of epithelial cells," Experimental Cell Research, vol. 297, no. 1, pp. 247-258, 2004.

[78] A. Traweger, R. Fuchs, I. A. Krizbai, T. M. Weiger, H.C. Bauer, and H. Bauer, "The tight junction protein $\mathrm{ZO}-2$ localizes to the nucleus and interacts with the heterogeneous nuclear ribonucleoprotein scaffold attachment factor-B," Journal of Biological Chemistry, vol. 278, no. 4, pp. 26922700, 2003.

[79] C. J. Gottardi, M. Arpin, A. S. Fanning, and D. Louvard, "The junction-associated protein, zonula occludens-1, localizes to the nucleus before the maturation and during the remodeling of cell-cell contacts," Proceedings of the National Academy of Sciences of the United States of America, vol. 93, no. 20, pp. 10779-10784, 1996.

[80] A. Renz and F. O. Fackelmayer, "Purification and molecular cloning of the scaffold attachment factor B (SAF-B), a novel human nuclear protein that specifically binds to S/MARDNA," Nucleic Acids Research, vol. 24, no. 5, pp. 843-849, 1996.

[81] O. Nayler, W. Stratling, J.-P. Bourquin, et al., "SAF-B protein couples transcription and pre-mRNA splicing to SAR/MAR elements," Nucleic Acids Research, vol. 26, no. 15, pp. 35423549, 1998.

[82] S. M. Townson, T. Sullivan, Q. Zhang, et al., "HET/SAF$\mathrm{B}$ overexpression causes growth arrest and multinuclearity and is associated with aneuploidy in human breast cancer," Clinical Cancer Research, vol. 6, no. 9, pp. 3788-3796, 2000.

[83] S. Oesterreich, A. V. Lee, T. M. Sullivan, S. K. Samuel, J. R. Davie, and S. A. W. Fuqua, "Novel nuclear matrix protein HET binds to and influences activity of the HSP27 promoter in human breast cancer cells," Journal of Cellular Biochemistry, vol. 67, no. 2, pp. 275-286, 1997.
[84] M. Huerta, R. Munoz, R. Tapia, et al., "Cyclin D1 is transcriptionally down-regulated by ZO-2 via an E box and the transcription factor c-Myc," Molecular Biology of the Cell, vol. 18, no. 12, pp. 4826-4836, 2007.

[85] R. Tapia, M. Huerta, S. Islas, et al., "Zona occludens2 inhibits cyclin D1 expression and cell proliferation and exhibits changes in localization along the cell cycle," Molecular Biology of the Cell, vol. 20, no. 3, pp. 1102-1117, 2009.

[86] M. S. Balda, M. D. Garrett, and K. Matter, "The ZO1-associated Y-box factor ZONAB regulates epithelial cell proliferation and cell density," Journal of Cell Biology, vol. 160, no. 3, pp. 423-432, 2003.

[87] M. S. Balda and K. Matter, "The tight junction protein ZO1 and an interacting transcription factor regulate ErbB-2 expression," EMBO Journal, vol. 19, no. 9, pp. 2024-2033, 2000.

[88] T. Sourisseau, A. Georgiadis, A. Tsapara, et al., "Regulation of PCNA and cyclin D1 expression and epithelial morphogenesis by the ZO-1-regulated transcription factor ZONAB/DbpA," Molecular and Cellular Biology, vol. 26, no. 6, pp. 2387-2398, 2006.

[89] A. Tsapara, K. Matter, and M. S. Balda, "The heat-shock protein Apg-2 binds to the tight junction protein $\mathrm{ZO}-1$ and regulates transcriptional activity of ZONAB," Molecular Biology of the Cell, vol. 17, no. 3, pp. 1322-1330, 2006.

[90] B. H. Keon, S. Schafer, C. Kuhn, C. Grund, and W. W. Franke, "Symplekin, a novel type of tight junction plaque protein," Journal of Cell Biology, vol. 134, no. 4, pp. 1003-1018, 1996.

[91] E. Kavanagh, M. Buchert, A. Tsapara, et al., "Functional interaction between the ZO-1 interacting transcription factor ZONAB/DbpA and the RNA processing factor symplekin," Journal of Cell Science, vol. 119, no. 24, pp. 5098-5105, 2006.

[92] A. Betanzos, M. Huerta, E. Lopez-Bayghen, E. Azuara, J. Amerena, and L. González-Mariscal, "The tight junction protein ZO-2 associates with Jun, Fos and C/EBP transcription factors in epithelial cells," Experimental Cell Research, vol. 292, no. 1, pp. 51-66, 2004.

[93] J. M. Daniel and A. B. Reynolds, "The catenin p120(ctn) interacts with Kaiso, a novel BTB/POZ domain zinc finger transcription factor," Molecular and Cellular Biology, vol. 19, no. 5, pp. 3614-3623, 1999.

[94] A. Traweger, C. Lehner, A. Farkas, et al., "Nuclear Zonula occludens-2 alters gene expression and junctional stability in epithelial and endothelial cells," Differentiation, vol. 76, no. 1, pp. 99-106, 2008.

[95] J. Lee, H. K. Kim, Y.-M. Han, and J. Kim, "Pyruvate kinase isozyme type M2 (PKM2) interacts and cooperates with Oct-4 in regulating transcription," International Journal of Biochemistry and Cell Biology, vol. 40, no. 5, pp. 1043-1054, 2008.

[96] M. Takahisa, S. Togashi, T. Suzuki, et al., "The Drosophila tamou gene, a component of the activating pathway of extramacrochaetae expression, encodes a protein homologous to mammalian cell- cell junction-associated protein $\mathrm{ZO}-1$," Genes and Development, vol. 10, no. 14, pp. 1783-1795, 1996.

[97] A. Chlenski, K. V. Ketels, G. I. Korovaitseva, M. S. Talamonti, R. Oyasu, and D. G. Scarpelli, "Organization and expression of the human zo-2 gene (tjp-2) in normal and neoplastic tissues," Biochimica et Biophysica Acta, vol. 1493, no. 3, pp. 319-324, 2000. 
[98] M. Reichert, T. Muller, and W. Hunziker, "The PDZ domains of zonula occludens- 1 induce an epithelial to mesenchymal transition of Madin-Darby canine kidney I cells. evidence for a role of $\beta$-catenin/Tcf/Lef signaling," Journal of Biological Chemistry, vol. 275, no. 13, pp. 9492-9500, 2000.

[99] E. S. Wittchen, J. Haskins, and B. R. Stevenson, "Exogenous expression of the amino-terminal half of the tight junction protein ZO-3 perturbs junctional complex assembly," Journal of Cell Biology, vol. 151, no. 4, pp. 825-836, 2000.

[100] J. Downward, "Targeting RAS signalling pathways in cancer therapy," Nature Reviews Cancer, vol. 3, no. 1, pp. 11-22, 2003.

[101] K. Takahashi, H. Nakanishi, M. Miyahara, et al., "Nectin/ PRR: an immunoglobulin-like cell adhesion molecule recruited to cadherin-based adherens junctions through interaction with afadin, a PDZ domain-containing protein," Journal of Cell Biology, vol. 145, no. 3, pp. 539-549, 1999.

[102] B. Boettner, E.-E. Govek, J. Cross, and L. Van Aelst, "The junctional multidomain protein AF-6 is a binding partner of the RaplA GTPase and associates with the actin cytoskeletal regulator profilin," Proceedings of the National Academy of Sciences of the United States of America, vol. 97, no. 16, pp. 9064-9069, 2000.

[103] T. Linnemann, M. Geyer, B. K. Jaitner, et al., "Thermodynamic and kinetic characterization of the interaction between the Ras binding domain of AF6 and members of the Ras subfamily," Journal of Biological Chemistry, vol. 274, no. 19, pp. 13556-13562, 1999.

[104] T. Yamamoto, N. Harada, K. Kano, et al., "The Ras target AF6 interacts with ZO-1 and serves as a peripheral component of tight junctions in epithelial cells," Journal of Cell Biology, vol. 139, no. 3, pp. 785-795, 1997.

[105] B. A. Glaunsinger, R. S. Weiss, S. S. Lee, and R. Javier, "Link of the unique oncogenic properties of adenovirus type 9 E4-ORF1 to a select interaction with the candidate tumor suppressor protein ZO-2," EMBO Journal, vol. 20, no. 20, pp. 5578-5586, 2001.

[106] C. H. Storrs and S. J. Silverstein, "PATJ, a tight junctionassociated PDZ protein, is a novel degradation target of highrisk human papillomavirus E6 and the alternatively spliced isoform 18 E6," Journal of Virology, vol. 81, no. 8, pp. 40804090, 2007.

[107] R. T. Javier, "Cell polarity proteins: common targets for tumorigenic human viruses," Oncogene, vol. 27, no. 55, pp. 7031-7046, 2008. 

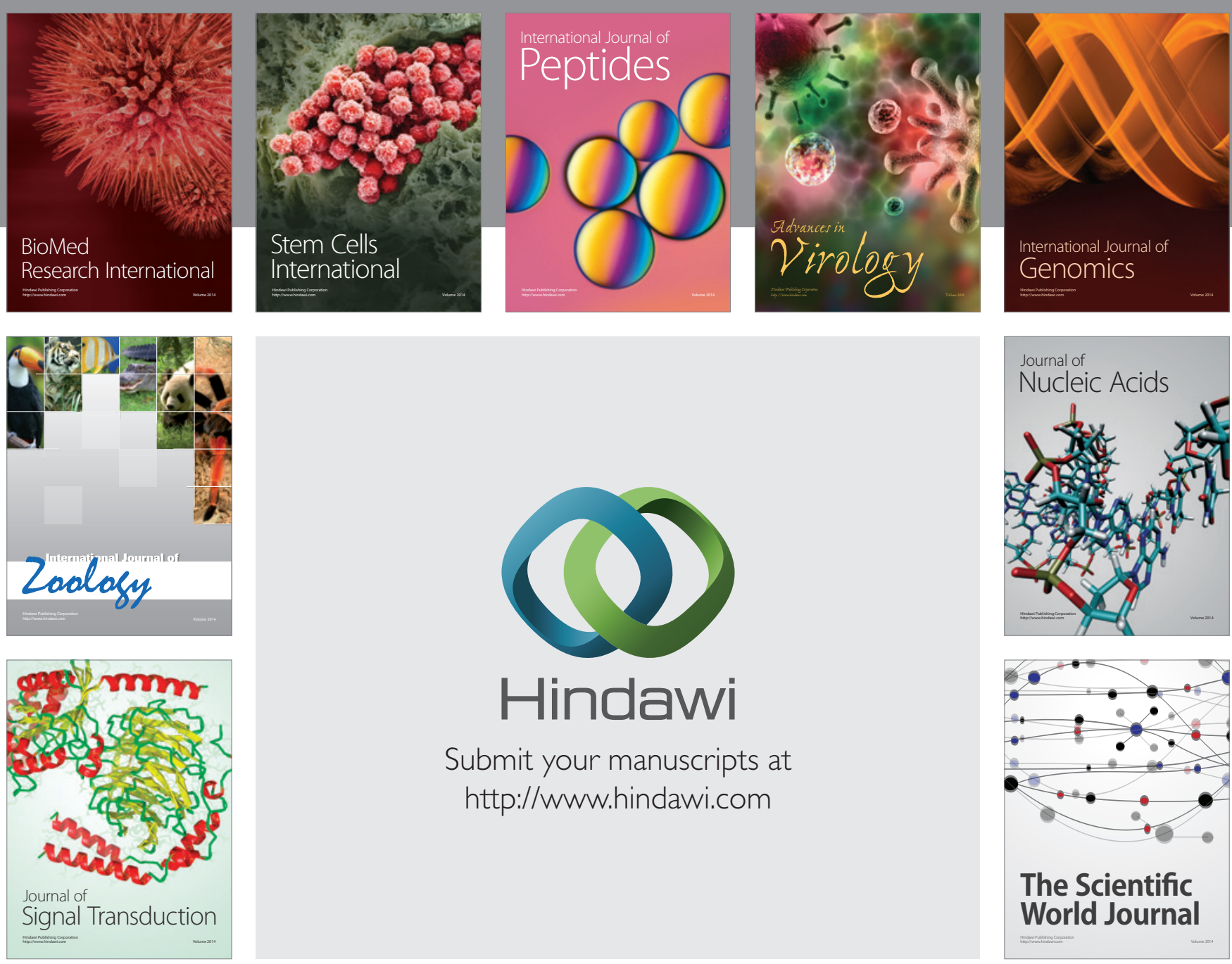

Submit your manuscripts at

http://www.hindawi.com
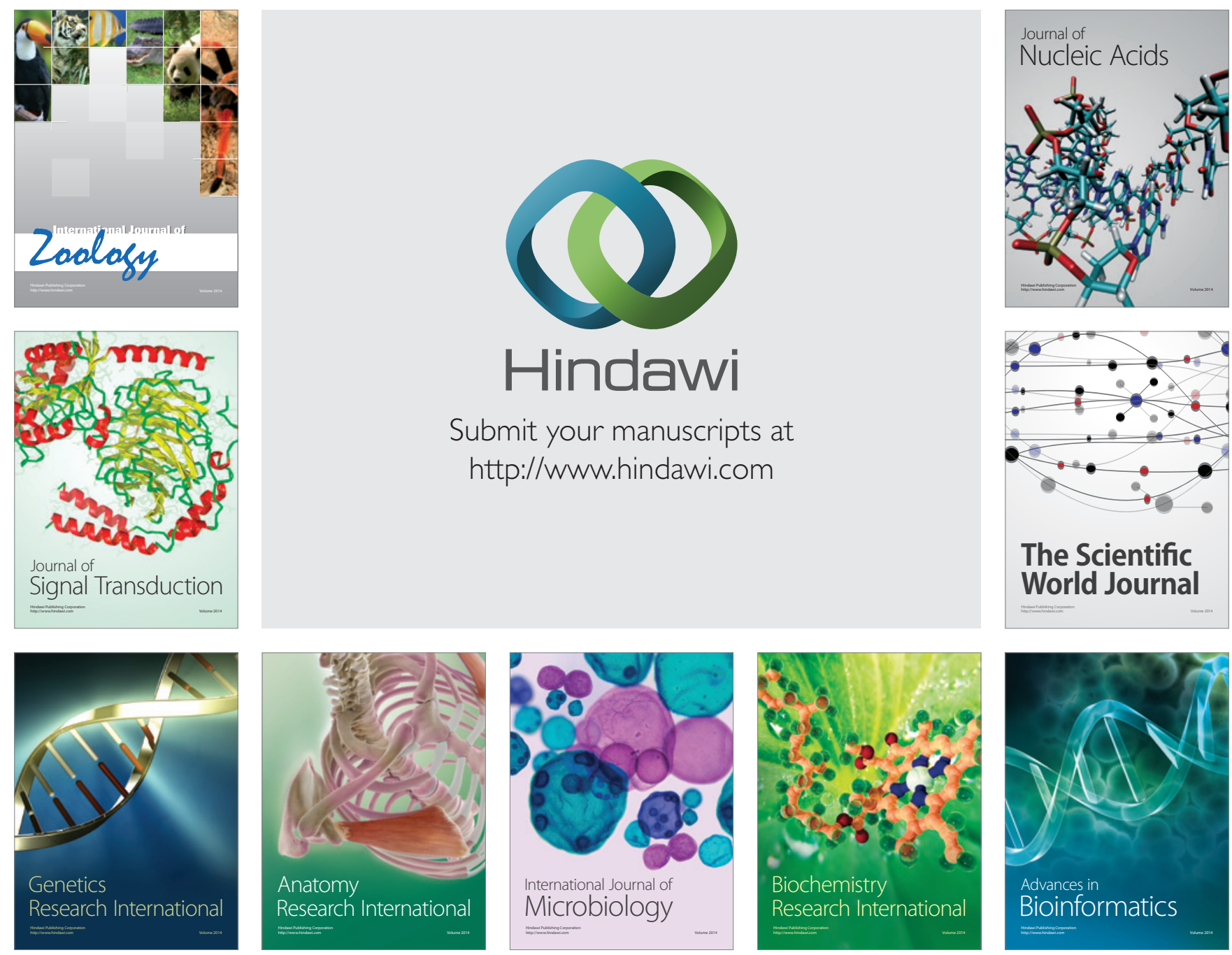

The Scientific World Journal
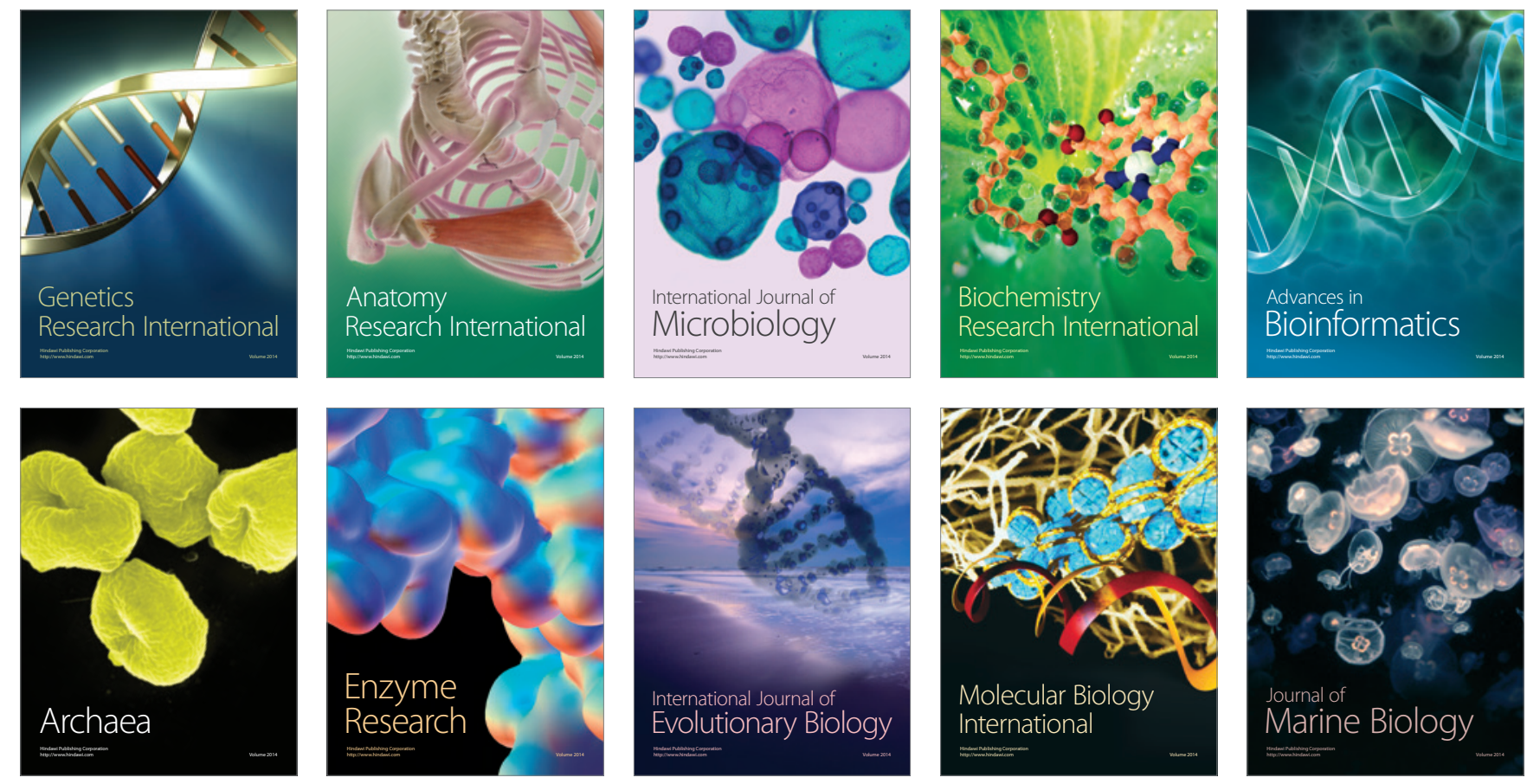